\title{
Efficacy of Home Phototherapy in Neonatal Jaundice
}

\author{
Saba Sardari ${ }^{1}$, Majid Mohammadizadeh ${ }^{2}$ and Mahboobeh Namnabati ${ }^{3,{ }^{*}}$ \\ ${ }^{1}$ Students Research Center, School of Nursing and Midwifery, Isfahan University of Medical Sciences, Isfahan, Iran \\ ${ }^{2}$ Department of Pediatrics, Isfahan University of Medical Sciences, Isfahan, Iran \\ ${ }^{3}$ Faculty of Nursing and Midwifery, Isfahan University of Medical Sciences, Isfahan, Iran \\ "Corresponding author: Nursing and Midwifery Care Research Center, Faculty of Nursing and Midwifery, Isfahan University of Medical Sciences, Isfahan, Iran. Tel: \\ +98-9133288250, Fax: +98-3137927573, Email: namnabat@nm.mui.ac.ir
}

Received 2018 July 26; Revised 2018 September 18; Accepted 2018 September 28.

\section{Abstract}

Background: Jaundice is one of the most common problems in the neonatal period. Phototherapy is one of the most commonly used treatments for jaundice that can be used as a simple, practical home-based treatment. Hospitalization during the first days of birth to conduct phototherapy may result in problems like nosocomial infections and mother separation from the baby.

Objectives: The aim of this study was to evaluate the efficacy of home phototherapy in the duration of treatment, mean bilirubin level, and complications.

Methods: This clinical trial was performed on newborns with jaundice in Isfahan health centers. The sample was randomly divided into two groups: Phototherapy at home (32 patients) and phototherapy at the hospital (32 patients). A demographic questionnaire and a researcher-made checklist were used to collect data on variables such as the duration of treatment, the frequency of treatment failure, mean bilirubin, and phototherapy complications.

Results: The mean duration of phototherapy in both groups was two days, which showed no significant difference $(P=0.32)$. The most common complication in both groups was skin rashes and restlessness, which also showed no significant between two groups $(P>0.05)$. There was no significant difference in terms of treatment failure $(P=0.246)$. Statistical tests also revealed that bilirubin reduction was the same in both groups.

Conclusions: Home phototherapy can be suggested as a safe treatment with no complication to the patients.

Keywords: Home Phototherapy, Complications, Hyperbilirubinemia, Neonatal

\section{Background}

The serum level of bilirubin is naturally elevated during the third to fifth day of life followed by a gradual decrease. Hyperbilirubinemia occurs when the indirect bilirubin level of the neonates' sera exceeds $1.5 \mathrm{mg} / \mathrm{dL}$. Proper management is important in the treatment and prevention of jaundice symptoms (1). Phototherapy is one of the most commonly used neonatal jaundice therapies in which the light energy converts insoluble and indirect bilirubin into direct and soluble bilirubin that can be excreted through the liver and kidneys (2). Light spectrum, radiation energy, and the exposed surface of the body can affect the effectiveness of phototherapy (3). In fact, the importance of neonatal jaundice treatment is not only due to the economic, social, and psychological consequences of the newborn hospitalization, but also because of the complications in the nervous system of the baby (4).

Phototherapy has been used to prevent neonates' mortality as much as oxygen (5). In a study in 2017, the re- searchers concluded that although phototherapy is a common practice in the NICUs, its control, care, and follow-up are necessary as it may result in side effects (6). Similar to many other therapies, phototherapy can lead to complications such as skin rashes, eye damage (light toxic effects on the retina, corneal scarring, and infectious conjunctivitis), hyperthermia, dehydration, and diarrhea, along with complications of the nervous system, if applied inappropriately (7). Hospitalization in the first days of birth for phototherapy may lead to nosocomial infections, separating the mother from the baby, a sense of having a sick newborn in the parents and relatives, waste of time, high cost of hospitalization, occupation of hospital beds (which can be used for more severe cases), and limitation of breastfeeding due to improper conditions (8).

Nursing home care is one of the nursing interventions (9). Home care, especially home phototherapy, is becoming increasingly popular and it is recognized as a safe and easy way to be applied at home under the supervision of experts. Despite the controversy about the safety and fea- 
sibility of this method, home phototherapy is currently used in the United States, Britain, Australia, Malaysia, and Iran (10). Considering the contradictory results of studies on home phototherapy, the Regional Child Health and Human Development Organization conducted a prospective case-control study on neonatal jaundice and responded to the ambiguities and questions about home phototherapy. Accordingly, home phototherapy was more effective and convenient for healthy, termed neonates than hospital phototherapy. Moreover, this therapeutic approach had no serious complications (11).

Nowadays, home phototherapy is very popular due to the importance of preventing mother-infant separation, as well as the continuity of care at home (12). On the other hand, home phototherapy, if not complying with standards and not supervised by qualified physicians and nurses, may lead to complications. Rogerson et al. believe that home-based phototherapy could be easily done, but it would be better if pediatricians and nurses provide the primary care and supervision instead of other groups who, for any reason, sometimes without the necessary expertise, provide phototherapy treatment equipment at home (13).

The major feature of home phototherapy is the lack of mother-infant separation (14). Neonatal and child health in adulthood is important (15-17). Phototherapy at home can be a proper substitute for hospital interventions if the parents are educated about home phototherapy it is done under the supervision of trained nurses. Regarding what mentioned above, home phototherapy is not officially practiced at medical centers and the health system still does not trust this method.

\section{Objectives}

The present study aimed to investigate the efficacy of home phototherapy and its effect on treatment duration, total bilirubin level, and treatment failure, as well as side effects.

\section{Methods}

In this clinical trial, the sample was randomly selected from Isfahan health centers from January to June 2017. Neonates who were diagnosed with physiologic jaundice confirmed by a physician to be a candidate for phototherapy with following inclusion criteria (according to home phototherapy guidelines approved by the American Academy Pediatrics (AAP)) were enrolled in the study: A term newborn with a total bilirubin level between 14 and $18 \mathrm{mg} / \mathrm{dL}$, an age of more than three days, a weight of more than 2500 grams, no risk symptoms such as mother-infant blood incompatibility, polycythemia, favism, Coombs' positive anemia, and no history of severe neonatal jaundice in the family (18). The sample was selected by a convenience sampling and divided into two groups of test (home phototherapy) and control (hospital phototherapy). Sampling continued until the desired sample size reached (32 neonates in each group). The research objectives were explained to the parents and written consent was obtained for the participation in the research. In this study, a standard phototherapy device was used. The tests of total bilirubin, blood group determination, and $\mathrm{CBC}$ were performed at the beginning of the treatment procedure and the results were recorded. The total bilirubin level of the newborns was measured daily and the results were used to decide on treatment continuation, discontinuation, or admission to the hospital. The infants' checklists were given to the parents while the researcher remained fully in contact with the parents. The demographic data, the prevalence of treatment failure, the complications of phototherapy, and the duration of treatment were collected for statistical analysis.

\section{Results}

64 healthy, term neonates were enrolled in the study. $62.5 \%$ of the neonates in the test group and $56.2 \%$ in the control group were boys. The chi-square test showed no significant difference between the two groups in terms of sex and blood type (P> 0.05) (Table 1). Based on the MannWhitney test, there was no significant difference between the two groups in terms of age and weight of the neonates $(P>0.05)$ (Table 2). The highest fetal age was 39 weeks and the independent $t$-test revealed no significant difference between the two groups in the fetal age $(\mathrm{P}>0.05)$. This test also indicated that there was no statistically significant difference in the required duration of phototherapy (2.28 in the test and 2.44 in the control groups) (2 days on average) $(P>0.05)$ (Table 3). Home phototherapy had two cases of failure (6.2\%). Based on the independent $t$-test, the mean bilirubin level (before and after treatment) showed no significant difference between the two groups $(\mathrm{P}>0.05)$ (Table 4). The frequency distribution of phototherapy complications is presented in Table 5.

\section{Discussion}

Due to the prevalence of chronic diseases in children and infants, attention to their health is important $(17,19)$. The study investigated the impact of home phototherapy on the treatment duration, complication prevalence, bilirubin mean, and treatment failure among neonatal 


\begin{tabular}{|c|c|c|c|c|}
\hline \multirow{2}{*}{ Variable } & \multirow{2}{*}{ Home Phototherapy } & \multirow{2}{*}{ Hospital Phototherapy } & \multicolumn{2}{|c|}{ Chi-Square Test } \\
\hline & & & $\chi^{2}$ & $\mathbf{P}$ \\
\hline Blood type & & & 6.27 & 0.28 \\
\hline A+ & $11(34.4)$ & $12(37.5)$ & & \\
\hline A- & $0(0)$ & $1(3.1)$ & & \\
\hline $\mathrm{B}+$ & $9(28.1)$ & $7(21.9)$ & & \\
\hline $\mathrm{O}+$ & $5(15.6)$ & $15.6(25)$ & & \\
\hline O- & $3(9.4)$ & $1(3.1)$ & & \\
\hline $\mathrm{AB}+$ & $4(12.5)$ & $3(9.4)$ & & \\
\hline Sex & & & 0.26 & 0.61 \\
\hline Male & $12(37.5)$ & $14(43.8)$ & & \\
\hline Female & $20(52.5)$ & $18(56.2)$ & & \\
\hline \multicolumn{5}{|c|}{${ }^{\mathrm{a}}$ Values are expressed as No. (\%). } \\
\hline \multirow{2}{*}{ Variable } & \multirow{2}{*}{ Home Phototherapy } & \multirow{2}{*}{ Hospital Phototherapy } & \multicolumn{2}{|c|}{ Mann-Whitney Test } \\
\hline & & & $\mathbf{Z}$ & $\mathbf{P}$ \\
\hline Calender age (day) & & & 0.70 & 0.48 \\
\hline $3-6$ & $15(46.8)$ & $18(56.2)$ & & \\
\hline $7-10$ & $11(34.4)$ & $9(28.1)$ & & \\
\hline $11-14$ & $6(18.8)$ & $5(15.7)$ & & \\
\hline Weight (gram) & & & 0.75 & 0.45 \\
\hline $2500-3000$ & $27(84.4)$ & $29(90.6)$ & & \\
\hline Over 3000 & $5(15.6)$ & $3(9.4)$ & & \\
\hline
\end{tabular}

${ }^{\mathrm{a}}$ Values are expressed as No. (\%).

\begin{tabular}{lccc}
\hline Table 3. The Mean Duration of Phototherapy in the Two Groups \\
\hline Group & Mean \pm SD & \multicolumn{2}{c}{ Independent $t$-Test } \\
\cline { 3 - 4 } & & $\boldsymbol{t}$ & P \\
\hline Home phototherapy & $2.28 \pm 0.63$ & 0.99 & 0.32 \\
Hospital phototherapy & $2.44 \pm 0.62$ & &
\end{tabular}

jaundice patients. Jaundice has many complications for children (20). In this study, A+ blood type had the highest frequency in the test and control groups with the prevalence of $37.5 \%$ and $34.4 \%$, respectively. In a study by Lavanya et al. in 2012, it was concluded that neonatal jaundice had a higher prevalence among infants with blood types of $A B$ and $A$. In that study, the highest prevalence was related to A+ (21). The mean of calendar age was 3 - 6 days, which was in agreement with the study of Khatami and Soltani in which the mean calendar age was reported to be 7.2 days.

The mean duration of phototherapy was 2 days, on av- erage, in both groups. In the study of Khatami and Soltani this parameter was $33 \mathrm{~h}(24-86 \mathrm{~h})$, which is in line with the results of the current study (22). The results of this study showed no statistically significant difference in the pre- and post-treatment bilirubin level of neonates from the two groups. This means that home and hospital phototherapy had the same impact on the bilirubin level.

The Fisher's exact test showed that on the first day, there was no significant difference in the frequency of fever between the two groups $(P>0.05)$. The chi-square test revealed no significant difference between the two groups in terms of the incidence of complications such as exanthem, weakness, bad lactation, and restlessness ( $P$ $>0.05)$. The frequency of fever was quite similar in the two groups and no omphalitis and conjunctivitis occurred in the two groups. In a study conducted by Barzgar et al. in 2005 , it was concluded that infection was more likely to occur in the hospital phototherapy group than in the home phototherapy group (23). In that study, 19 neonates 


\begin{tabular}{|c|c|c|c|c|}
\hline \multirow{2}{*}{ Time } & \multirow{2}{*}{ Home Phototherapy } & \multirow{2}{*}{ Hospital Phototherapy } & \multicolumn{2}{|c|}{$t$-Test } \\
\hline & & & $t$ & $\mathbf{P}$ \\
\hline First day (admission day) & $16.02 \pm 1.17$ & $16.46 \pm 1.47$ & 1.31 & 0.19 \\
\hline Second day & $12.24 \pm 1.67$ & $12.43 \pm 2.48$ & 0.37 & 0.71 \\
\hline Third day & $10.25 \pm 0.40$ & $10.08 \pm 1.07$ & 0.64 & 0.53 \\
\hline \multicolumn{5}{|c|}{${ }^{\mathrm{a}}$ Values are expressed as mean $\pm \mathrm{SD}$} \\
\hline \multirow{2}{*}{ Time/Complications } & \multirow{2}{*}{ Home Phototherapy } & \multirow{2}{*}{ Hospital Phototherapy } & \multicolumn{2}{|c|}{ Chi-Square } \\
\hline & & & $\chi^{2}$ & $\mathbf{P}$ \\
\hline \multicolumn{5}{|l|}{ First day } \\
\hline Skin rashes & $13(40.6)$ & $16(50)$ & 0.57 & 0.45 \\
\hline Diarrhea & $3(9.4)$ & $3(9.4)$ & - & 1 \\
\hline Fever & $1(3.1)$ & $3(9.4)$ & - & 0.31 \\
\hline Weakness & $6(18.8)$ & $10(31.2)$ & 1.33 & 0.25 \\
\hline Weak lactation & $7(21.9)$ & $13(40.6)$ & 2.62 & 0.11 \\
\hline Restlessness & $12(37.5)$ & $8(25)$ & 1.16 & 0.28 \\
\hline Omphalitis & $0(0)$ & $0(0)$ & - & 1 \\
\hline Conjunctivitis & $0(0)$ & $0(0)$ & - & 1 \\
\hline \multicolumn{5}{|l|}{ Second day } \\
\hline Skin rashes & $16(50)$ & $15(46.9)$ & 0.06 & 0.80 \\
\hline Diarrhea & $1(3.1)$ & $2(6.2)$ & - & 0.5 \\
\hline Fever & $0(0)$ & $2(6.2)$ & - & 0.25 \\
\hline Weakness & $7(21.9)$ & $7(21.9)$ & - & 1 \\
\hline Weak lactation & $5(15.6)$ & $8(25)$ & 0.87 & 0.35 \\
\hline Restlessness & $9(28.1)$ & $9(28.1)$ & - & 1 \\
\hline Omphalitis & $0(0)$ & $1(3.1)$ & - & 0.5 \\
\hline Conjunctivitis & $0(0)$ & $0(0)$ & - & 1 \\
\hline \multicolumn{5}{|l|}{ Third day } \\
\hline Skin rashes & $6(18.8)$ & $7(21.9)$ & 0.10 & 0.76 \\
\hline Diarrhea & $0(0)$ & $0(0)$ & - & 1 \\
\hline Fever & $0(0)$ & $0(0)$ & - & 1 \\
\hline Weakness & $1(3.1)$ & $2(6.2)$ & - & 50 \\
\hline Weak lactation & $2(6.2)$ & $2(6.2)$ & - & 1 \\
\hline Restlessness & $2(6.2)$ & $4(12.5)$ & - & 0.34 \\
\hline Omphalitis & $0(0)$ & $0(0)$ & - & 1 \\
\hline Conjunctivitis & $0(0)$ & $0(0)$ & - & 1 \\
\hline
\end{tabular}

${ }^{\mathrm{a}}$ Values are expressed as No. (\%).

from the hospital group were found with conjunctivitis and seven suffered from omphalitis, which is not in line with our study. In addition, due to inadequate monitoring and non-compliance with the ambient temperature, the neonates can easily develop hypothermia or hyperthermia during phototherapy (24). 
In Khatami and Soltani's study, the results showed seven cases of body temperature imbalance in the home phototherapy group; the frequency of infant's restlessness in the early hours of phototherapy was 33\% and that of the subsequent problem (intolerance to eye protection) was 27\%. In a study by Eghbalian in 2009, the most common complications of phototherapy were diarrhea, cutaneous rashes, skin discoloration, hyperthermia, and intangible fluid excretion. In this study, some of these complications were found in both groups. It seems that the increased awareness of the importance of jaundice and early referring to hospital among families can be helpful in reducing the complications of jaundice (6). In the group of hospital phototherapy, there were no cases of treatment failure while two failures were recorded in the home phototherapy group (6.2\%). This difference was not significant according to Fisher's exact test $(\mathrm{P}=0.246)$. In Khatami and Soltani's study, eight failures were reported for home phototherapy, which is much higher than the results of the present study. It is noteworthy that, the reason for the higher rate of success in home-based treatments including phototherapy could be due to the lack of up-to-date relevant articles in Iran (in this field), the difference in the level of people's demands from past to present, higher willingness to carry out nursing care at home, increased information and improved public and families awareness, the greater sensitivity of parents to their newborns' treatment and, of course, declined number of children per family which has resulted in the more attention of parents to their children.

The limitation of this study was that despite that home phototherapy is suggested by the AAP, it is not officially accepted for the treatment of neonates' jaundice; hence, the researchers faced many problems to convince people to cooperate.

\subsection{Conclusions}

Due to the lower incidence of complications and the same duration of treatment, as well as the lack of treatment failure, it can be concluded that home phototherapy can be a suitable alternative for treating neonates' jaundice. Therefore, this method is recommended for neonatal jaundice treatment through correct training of phototherapy at home.

\section{Footnotes}

Clinical Trial Registration: IRCT20180527039869N1.

Conflict of Interests: No conflict of interests is reported.

Ethical Considerations: IR.mui.rec.1396.3.706.
Funding/Support: Student Research Committee, Isfahan University of Medical Sciences, Isfahan, Iran (grant number: 3007220) funded the study.

Patient Consent: Patients did not pay for the treatment and informed consent was obtained from them.

\section{References}

1. Maisels MJ, McDonagh AF. Phototherapy for neonatal jaundice. $N$ Engl J Med. 2008;358(9):920-8. doi: 10.1056/NEJMct0708376. [PubMed: 18305267].

2. Kliegman RM, Stanton BMD, Geme JS, Schor NF. Nelson textbook of pediatrics. 20th ed. Philadelphia: Saunders; 2016.

3. Hansen TW. Twists and turns in phototherapy for neonatal jaundice. Acta Paediatr. 2010;99(8):1117-8. doi: 10.1111/j.1651-2227.2010.01898.x. [PubMed: 20528792].

4. Boskabadi H, Khakshoor A, Khorashadi Zadeh F, Taherpour M, Esmaily $\mathrm{H}$. [Prenatal complications causing neonatal jaundice in Ghaem Hospital, Mashhad-Iran]. J North Khorasan Univ Med Sci. 2011;3(2):7-11. Persian.

5. Stokowski LA. Fundamentals of phototherapy for neonatal jaundice. Adv Neonatal Care. 2006;6(6):303-12. doi: 10.1016/j.adnc.2006.08.004. [PubMed: 17208161].

6. Mreihil K, Benth JS, Stensvold HJ, Nakstad B, Hansen TWR, Norwegian NPSG, et al. Phototherapy is commonly used for neonatal jaundice but greater control is needed to avoid toxicity in the most vulnerable infants.Acta Paediatr.2018;107(4):611-9. doi:10.1111/apa.14141.[PubMed: 29119603].

7. Eghbalian F, Monsef AR. [comparison of the efficacy and complications between two dimensional phototherapy (cylindrical) and uni dimensional phototherapy (double) in neonatal unconjugated hyperbilirubinemia]. JUrmia Univ Med Sci. 2010;20(4):254-60. Persian.

8. Boskabadi H, Ashrafzadeh F, Azarkish F, Khakshour A. Complications of neonatal jaundice and the predisposing factors in newborns. $J$ Babol Univ Med Sci. 2015;17(9):7-13.

9. Borji M. Investigating the effect of home care on death anxiety in patients with gastrointestinal cancer. Govaresh. 2017;22(2):131-2.

10. Snook J. Is home phototherapy in the term neonate with physiological jaundice a feasible practice? a systematic literature review. J Neonatal Nurs. 2017;23(1):28-39. doi: 10.1016/j.jnn.2016.08.001.

11. Adlina S, Ambigga D, Narimah AHH, Ridha A. Use of home phototheraphy for neonatal jaudice. Malaysian J Public Health Med. 2007;7(2):4952.

12. Namnabati M, Taleghani F, Sadeghnia A. Home-based care needs of preterm infants discharged early from the neonatal intensive care unit: A descriptive qualitative study. Iran J Neonatol IJN. 2017;8(4):7482. doi: 10.22038/IJN.2017.21890.1253.

13. Rogerson AG, Grossman ER, Gruber HS, Boynton RC, Cuthbertson JG. 14 years of experience with home phototherapy. Clin Pediatr (Phila). 1986;25(6):296-9. doi: 10.1177/000992288602500602. [PubMed: 3698452].

14. Walls M, Wright A, Fowlie P, Irvine L, Hume R. Home phototherapy in the United Kingdom. Arch Dis Child Fetal Neonatal Ed. 2004;89(3):F282. [PubMed: 15102743]. [PubMed Central: PMC1721662].

15. Kazeminezhad B, Taghinejad H, Borji M, Tarjoman A. The effect of self-care on glycated hemoglobin and fasting blood sugar levels on adolescents with diabetes. J Compr Ped. 2018;In Press(In Press). doi: 10.5812/compreped.62661.

16. Borji M, Tarjoman A, Nejad HT, Meymizade M, Nariman S, Safari S. relationship between knowledge-skill and importance of physical examination for children admitted to infectious wards: Examining nurses' points of view. J Compr Ped. 2018;9(1). doi: 10.5812/compreped.63292. 
17. Tarjoman A, Vasigh A, Safari S, Borji M. Pain management in neonatal intensive care units: A cross sectional study of neonatal nurses in Ilam City. J Neonatal Nur. 2018. doi:10.1016/j.jnn.2018.08.006.

18. American Academy of Pediatrics Subcommittee on Hyperbilirubinemia. Management of hyperbilirubinemia in the newborn infant 35 or more weeks of gestation. Pediatrics. 2004;114(1):297-316. doi: 10.1542/peds.114.1.297. [PubMed: 15231951].

19. Vasigh A, Abdi A, Borji M, Tarjoman A. The prevalence of neuropathy among type 1 diabetic adolescents in Iran: A systematic review and meta-analysis. Int J Adolesc Med Health. 2019. doi: 10.1515/ijamh-20180223. [PubMed: 30685741].

20. Borji M, Moradi M, Otaghi M, Tartjoman A. Relationship between nutritional status, food insecurity, and causes of hospitalization of children with infectious diseases.J Compr Ped. 2018;9(2). doi: 10.5812/com- preped.63870.

21. Lavanya KR, Jaiswal A, Reddy P, Murki S. Predictors of significant jaundice in late preterm infants. Indian Pediatr. 2012;49(9):717-20. [PubMed: 22791669].

22. Khatami F, Soltani M. [Home phototherapy; an alternative method for treatment of jaundice in healthy-term newborns]. Iran J Ped. 2007;17(Suppl 2):193-8. Persian.

23. Barzgar M, Valizadeh S, Farshbaf F, Kargar M. Comparison of homebased and hospital-based phototherapy in healthy, term neonates with hyperbilirubinemia. Tabriz Med J. 2005;27(3):19-25.

24. Donneborg ML, Knudsen KB, Ebbesen F. Effect of infants' position on serum bilirubin level during conventional phototherapy. Acta Paediatr. 2010;99(8):1131-4. doi: 10.1111/j.1651-2227.2010.01885.x. [PubMed: 20528799]. 